\title{
Species-specific effects of turbidity on the physiology of imperiled blackline shiners Notropis spp. in the Laurentian Great Lakes
}

\author{
Suzanne M. Gray ${ }^{1,4, *}$, Laura H. McDonnell ${ }^{1}$, Nicholas E. Mandrak ${ }^{2}$, \\ Lauren J. Chapman ${ }^{1,3}$ \\ ${ }^{1}$ Department of Biology, McGill University, Montreal, QC H3A 1B1, Canada \\ ${ }^{2}$ Department of Biological Sciences, University of Toronto Scarborough, Toronto, ON M1C 1A4, Canada \\ ${ }^{3}$ Wildlife Conservation Society, Bronx, NY 10460, USA \\ ${ }^{4}$ Present address: School of Environment and Natural Resources, The Ohio State University, Columbus, OH 43210, USA
}

\begin{abstract}
Increased sedimentary turbidity associated with human activities is often cited as a key stressor contributing to the decline of fishes globally. The mechanisms underlying negative effects of turbidity on fish populations have been well documented, including effects on behavior (e.g. visual impairment) and/or respiratory function (e.g. clogging of the gills); however, the longterm physiological consequences are less well understood. The decline or disappearance of several blackline shiners Notropis spp. in the Laurentian Great Lakes has been associated with increased turbidity. Here, we used non-lethal physiological methods to assess the responses of 3 blackline shiners under varying degrees of threat in Canada (Species at Risk Act; pugnose shiner $N$. anogenus: endangered; bridle shiner $N$. bifrenatus: special concern; blacknose shiner $N$. heterolepis: common) to increased turbidity. Fish were exposed for 3 to 6 mo to continuous low levels of turbidity ( 7 nephelometric turbidity units, NTU). To test for effects on respiratory function, we measured both resting metabolic rate (RMR) and critical oxygen tension (the oxygen partial pressure at which the RMR of fish declines). No change in RMR was detected across species or in clear versus turbid treatments. However, critical oxygen tensions were negatively affected by longterm exposure to low levels of sedimentary turbidity in the 2 imperiled species, viz. pugnose and bridle shiner, but not in the more common blacknose shiner. Variation in effects of turbidity on respiratory performance suggests differential sensitivity to turbidity, which may contribute to the current conservation status of the 3 species.
\end{abstract}

KEY WORDS: Sedimentary turbidity - Critical oxygen tension - Resting metabolic rate · Conservation physiology $\cdot$ Pugnose shiner $\cdot$ Bridle shiner $\cdot$ Blacknose shiner

\section{INTRODUCTION}

The loss of aquatic biodiversity globally is ubiquitous, but the underlying mechanisms driving species declines are not always well understood. This knowledge is necessary for assessing critical habitat needs of imperiled species to facilitate their conservation and restoration (Rosenfeld \& Hatfield 2006). In aquatic habitats, increases in sediment flux associated with human activities including deforestation,

\footnotetext{
${ }^{*}$ Corresponding author: gray.1030@osu.edu
}

agriculture, and urbanization are pushing turbidity (suspended particulates) levels over natural ranges for prolonged periods (Kemp et al. 2011). Increased turbidity, and associated stressors on aquatic systems such as decreased dissolved oxygen and increased temperature, have been correlated with the loss of many freshwater fishes (Ricciardi \& Rassmusen 1999, Donohue \& Garcia Molinos 2009); however, less is known about the ways in which increased turbidity influences fitness. Sublethal behavioral and physio-

() The authors 2016. Open Access under Creative Commons by Attribution Licence. Use, distribution and reproduction are unrestricted. Authors and original publication must be credited. 
logical experiments can be used to determine the direct effects of environmental stressors, such as turbidity, on individual fish (Newcombe \& MacDonald 1991), providing managers with the evidence needed to implement recovery actions.

Increased sedimentary turbidity can directly affect fish through changes in behavior associated with reduced visual abilities (e.g. foraging and predatorprey relationships, reviewed by Collins et al. 2011); loss of mating opportunities (e.g. Candolin et al. 2007); gill damage (e.g. Sutherland \& Meyer 2007); and reduction in swimming performance (Gray et al. 2014), growth (e.g. Sutherland \& Meyer 2007), and survival (e.g. egg-smothering, Gray et al. 2012). However, less is known about the direct influence of long-term exposure on the underlying physiological processes that might hinder growth and survival, such as oxygen uptake and metabolism. Here, we investigated effects of long-term (>3 mo) exposure to low levels ( $\sim 7$ nephelometric turbidity units, NTU) of sedimentary turbidity on 3 blackline shiner species (Notropis spp.) from the Laurentian Great Lakes, 2 of which are imperiled (Gray et al. 2014) and have disappeared from historically clear, but now turbid, waters (Holm \& Mandrak 2002).

Several blackline shiners have declining or extirpated populations: these small, rare minnows are typically found in clear, heavily vegetated, shallow areas and are notably absent from sites with increased turbidity (Trautman 1981, Holm \& Mandrak 2002). Pugnose shiner $N$. anogenus is listed as 'endangered' under the Canadian Species at Risk Act (Holm \& Mandrak 2002), and the bridle shiner N. bifrenatus is considered of 'special concern.' The congeneric blacknose shiner $N$. heterolepis is considered threatened in several US states but is not imperiled in Canada. Pugnose and bridle shiners are typically found in water with <2.0 NTU (Gray et al. 2014) and are absent from more turbid waters (Trautman 1981, Trebitz et al. 2007). In a previous study (Gray et al. 2014), we found significant differences in schooling behavior between clear- and turbid-acclimated fish, with fewer pugnose and bridle shiners schooling as turbidity increased compared to no change in behavior in several other species, including blacknose shiner. Additionally, we found species-specific variation in swimming performance, an indicator of aerobic metabolism (Brett 1964), associated with turbidity acclimation only in the 2 most imperiled shiners. The ability of fishes to uptake dissolved oxygen over sensitive gill structures is essential to their survival; therefore, damage to gills caused by abrasive particulates or clogging of the gills is expected to decrease the efficiency of aerobic respi- ration. In the endangered pugnose shiner, fish acclimated to turbid waters had a lower critical swimming speed relative to clear-water-acclimated fish, suggesting a decline in aerobic capacity (Gray et al. 2014).

Spotfin chub Erimonax monachus juveniles held at 55 NTU displayed extensive gill damage and reduced specific growth rate after only $21 \mathrm{~d}$ of exposure to sedimentary turbidity (Sutherland \& Meyer 2007). The mechanism of reduced growth rate was speculated to be associated with reduced feeding efficiency and impaired respiration. A decrease in respiratory efficiency may also be reflected in changes in metabolic rate and the ability to regulate metabolism in response to changes in the environment. In fishes, resting or routine metabolic rate $\left(\mathrm{RMR}_{i}\right.$ measured when the fish is completely at rest; Brett 1964) is an indicator of the amount of energy required for maintenance; thus, an elevated RMR results in a higher energy demand for any activity in addition to maintenance. RMR varies inter- and intra-specifically in ectothermic fishes experiencing different environmental conditions (e.g. McDonnell \& Chapman 2015, Metcalfe et al. 2016). For example, under hypoxic conditions (i.e. low dissolved oxygen concentration), some fishes reduce their metabolic rates to decrease oxygen demands (Chapman 2015). Therefore, if suspended sediments cause abrasion or clogging of the gills, fish may reduce their metabolic rate to compensate for reduced efficiency of oxygen uptake. Many fish are oxyregulators, maintaining a stable rate of oxygen consumption $\left(\mathrm{VO}_{2}\right)$ over a wide range of dissolved oxygen (DO) levels until reaching their critical oxygen tension $\left(P_{\text {crit }}\right)$ beyond which $\mathrm{VO}_{2}$ becomes oxygen-dependent, decreasing as DO declines (Ultsch et al. 1978). If respiratory function is compromised (e.g. due to gill clogging or damage), then we expect $P_{\text {crit }}$ to be higher, reflecting increased cost of oxygen uptake.

Here, we provide a direct test of the influence of prolonged exposure to low levels of sedimentary turbidity on the physiology of 2 imperiled, and 1 more common, blackline shiners. We acclimated wildcaught fish to either clear or low turbidity conditions for several months and then tested for differences in RMR and $P_{\text {crit }}$ between and among treatments and species.

\section{MATERIALS AND METHODS}

\section{Fish collection and maintenance}

Adults of 3 species ( $\mathrm{n} \sim 40$ of each species) were collected from the St. Lawrence River, between 
Gananoque $\left(44^{\circ} 24^{\prime} 42^{\prime \prime} \mathrm{N}, 75^{\circ} 53^{\prime} 37^{\prime \prime} \mathrm{W}\right)$ and Cornwall ( $\left.45^{\circ} 0^{\prime} 4^{\prime \prime} \mathrm{N}, 74^{\circ} 41^{\prime} 8^{\prime \prime} \mathrm{W}\right)$, Ontario, Canada, between September and November 2011. Pugnose and bridle shiners were collected from a clear $(<2.0 \mathrm{NTU}$ over 3 sampling years; Gray et al. 2014), heavily vegetated shallow bay, while blacknose shiner were found in heavily vegetated, protected wetland channels. Habitat descriptions are based on qualitative observations but are typical of each species (details in Gray et al. 2014). Fishes were caught using a $10.0 \mathrm{~m}$ seine net $(0.5 \mathrm{~cm}$ mesh size $)$ deployed from a boat, immediately identified to species, and transported in coolers with aerated river water and vegetation to mitigate sloshing, to McGill University (Quebec, Canada).

Fishes were maintained at $18^{\circ} \mathrm{C}$, with a $12 \mathrm{~h}$ light: dark cycle in an environmentally controlled chamber at McGill University. Fish were fed frozen blood worms daily ad libitum. Species were held separately in 401 aquaria (6-8 fish per aquarium, 5 aquaria for each species) and allowed to acclimate to laboratory conditions for 1 mo before treatments were initiated. Turbidity, created using a solution of bentonite clay suspended in water (30 $\left.\mathrm{mg} \mathrm{l}^{-1}\right)$, was incrementally increased by adding $5 \mathrm{ml} \mathrm{d}^{-1}$ of the solution to turbid treatment aquaria (3 for each species) over a $\sim 2 \mathrm{wk}$ period and maintained at a mean $( \pm \mathrm{SE}$ ) turbidity of $7.31( \pm 0.2)$ NTU for at least 3 mo before physiological trials commenced (see Gray et al. 2014 for details). Trials were run over a 4 mo period. The 2 remaining aquaria per species were maintained at a mean turbidity level of $0.36( \pm 0.02)$ NTU and served as the clear control treatment. Turbidity (NTU) was measured weekly in every aquarium using a LaMotte 2020e turbidimeter ( \pm 0.2 NTU accuracy). Other water quality variables (temperature, DO, conductivity) were held constant and monitored weekly with a YSI Pro2030 multimeter probe. For each species, fish for metabolic rate trials were selected haphazardly from the 3 turbid tanks and both clear tanks to produce an average sample size of 6 fish treatment ${ }^{-1}$ for each species. Mortality occurred across the posttransport acclimation and 4 mo of trials, but was similar across species and treatments.

\section{Physiological trials}

Metabolic rates and $P_{\text {crit }}$ were measured using Loligo AutoResp intermittent flow-through respirometry equipment and software (Loligo Systems). The system consisted of a glass chamber in which the fish was placed, with a flush pump connected to one end and a separate temperature regulation unit. The glass chamber was $149.0 \mathrm{ml}$ in volume, $4.5 \mathrm{~cm}$ in diameter and $7.8 \mathrm{~cm}$ in length, contributing to a total system water volume of $157.0 \mathrm{ml}$. When the system is open (on 'Flush' setting) the glass chamber is flushed continuously with the aerated water from the ambient tank. The system was filled with NovAqua $(5 \mathrm{ml}$ $\mathrm{l}^{-1}$ ) treated water and closed to estimate $\mathrm{VO}_{2}$ by following the progression of oxygen decline. The chamber was covered with an opaque barrier with a small viewing port to minimize disturbance to the fish. Flow in the chamber during acclimation and experiment was set to a very low flow rate of approximately $0.17 \mathrm{~cm} \mathrm{~s}^{-1}$ (determined using a flow-rate calibration dye method) to keep water adequately mixed. Oxygen and temperature levels in the buffer tank surrounding the chamber were monitored and regulated by OXY-REG and TEMP-REG probes, respectively (Loligo Systems). Temperature during overnight acclimation was set to $18.1^{\circ} \mathrm{C}$ and varied little $\left( \pm 0.23^{\circ} \mathrm{C}\right)$. The average temperature throughout critical tension runs was $18.2^{\circ} \mathrm{C}( \pm 0.1)$. The oxygen in the chamber was measured using a Fibox3 fiberoptic oxygen probe and optical oxygen sensor (Loligo Systems; detection limit 15 ppb, 0-100\% oxygen). The 0 and $100 \%$ oxygen settings for both the chamber and buffer tank probes were re-calibrated regularly. Controls were run with an empty respirometer every week to determine background consumption rates. Fish were starved for $24 \mathrm{~h}$ prior to experiments to ensure a post-absorptive state (Clark et al. 2013). Individuals were weighed $(\mathrm{g})$ and measured (standard length, SL; $\mathrm{cm}$ ) before being placed in the chamber. Separate experiments were conducted to measure the build-up of waste products during respirometry experiments, but showed no trace of either nitrite or ammonia post-trial. Each fish was acclimated to the chamber for a minimum of $7 \mathrm{~h}$ overnight prior to the start of the trial. All trials were conducted using clear (turbidity $\sim 0$ NTU) water due to the sensitivity of the respirometry set-up to the clay particles.

The chamber was completely flushed with aerated water to remove any waste build-up before being closed to begin the critical tension trial. RMR values were obtained from the start of the trial, by calculating $\mathrm{VO}_{2}$ every $5 \mathrm{~min}$. Only $\mathrm{VO}_{2}$ values recorded up until $45 \mathrm{~min}$ prior to the fish attaining its $P_{\text {crit }}$ were used in calculations to ensure that the average rate was still oxygen-independent. This was also done in order to standardize methods between trials, as some fish had higher $\mathrm{VO}_{2}$ rates and thus shorter trial duration. Overall, resting $\mathrm{VO}_{2}$ values obtained during the 
period of oxy-regulation were averaged for each individual $\left(\mathrm{VO}_{\text {2obs }}\right)$ (He et al. 2015, Yang et al. 2015) and then mass-adjusted, using the body mass of the tested fish (mass ${ }_{\text {obs }}$ ) to obtain final RMR values with the following equation:

$$
\mathrm{RMR}=\mathrm{VO}_{2 \mathrm{obs}} \times\left(\text { mass }_{\text {mean }} / \text { mass }_{\text {obs }}\right)^{b}
$$

where $b$ is the slope of the regression of body mass vs. $\mathrm{VO}_{2}$ (both log-transformed) and mass mean is the average mass of all tested fish (Hendry \& Taylor 2004, Reardon et al. 2011).

The $\mathrm{VO}_{2}$ vs. time graph in the AutoResp software was observed so as to pinpoint the point of conversion from regulation to conformation, informed by average $\mathrm{VO}_{2}$ values calculated in real-time by the software every $10 \mathrm{~min}$. Afterwards, to more precisely calculate $P_{\text {crit }}$ a modified Yeager and Ultsch program (Reardon \& Chapman 2010) was used to convert oxygen (\% saturation) and temperature measures from the AutoResp software output to partial pressure of oxygen $(\mathrm{mm} \mathrm{Hg})$, used in calculating $P_{\text {crit }}$ values. Once $P_{\text {crit }}$ was clearly attained, the chamber was set to 'Flush,' and the fish was allowed to recover for 30 min before being removed from the chamber.

We used 2 statistical approaches. First, ANOVA was used to test for differences in mass-adjusted RMR and $P_{\text {crit }}$ with species and treatment (turbid vs. clear) as fixed factors. We followed up with separate post-hoc ANOVAs on the imperiled group (pugnose and bridle shiners) with species and treatment as fixed effects and non-imperiled blacknose shiners with treatment as the fixed effect. $P_{\text {crit }}$ data were log transformed to improve normality and stabilize the variance. The term 'tank' (nested within treatment and species) was non-significant $(0.286<\mathrm{p}<0.886)$ in all cases and was thus removed from all final models. We also tested for effects of body size on $P_{\text {crit }}$ (log transformed) of each species separately, with treatment as the fixed effect and body mass (log transformed) as the covariate. Because we found no significant effects of body size, it was not included as a covariate in the models above.

\section{RESULTS}

Fishes $(\mathrm{n}=37)$ used in the experiment ranged from 2.7 to $5.4 \mathrm{~cm} \mathrm{SL}$, while mass ranged from 0.33 to
$1.75 \mathrm{~g}$ (Table 1). The trial period (closed system) lasted an average of $8.7 \mathrm{~h}$, while mean acclimation time (system open) was $15.0 \mathrm{~h}$. In certain cases, control rates were considered too high $(>35 \%$ of $\mathrm{VO}_{2}$ ) to obtain accurate $\mathrm{VO}_{2}$ rates, and thus, 3 fish were eliminated from the RMR analysis. Therefore, a total of 34 RMR values were measured and 37 $P_{\text {crit }}$ values were attained among the 3 shiner species across both treatments (clear and turbid; Table 1).

There was no significant effect of species $\left(F_{1,28}=\right.$ $0.946, \mathrm{p}=0.400)$, turbidity treatment $\left(F_{1,28}=0.778\right.$, $\mathrm{p}=0.385)$, or their interaction $\left(F_{1,28}=0.001, \mathrm{p}=\right.$ 0.999) on RMR when all 3 species were included in the model (Fig. 1A). $P_{\text {crit }}$ was significantly higher for fish acclimated to turbid versus non-turbid treatments $\left(F_{1,31}=6.106, \mathrm{p}=0.019\right)$. We did not detect a significant effect of species $\left(F_{1,31}=0.138\right.$, $\mathrm{p}=0.871)$ or the interaction of species and treatment $\left(F_{1,31}=1.192, \mathrm{p}=0.317\right)$; however, visual inspection of the data (Fig. 1B) suggested that the treatment effect differed between the imperiled species and the common blacknose shiner. We therefore proceeded with separate post-hoc ANOVAs for the imperiled and common species. Again, there was no significant effect of turbidity treatment on RMR for the non-imperiled blacknose shiner or for the imperiled species (Table 2, Fig. 1A). Interestingly, $P_{\text {crit }}$ was significantly higher for the imperiled group when acclimated to turbid versus clear treatments, but there was no effect of turbidity on the $P_{\text {crit }}$ of the more common blacknose shiner (Table 2, Fig. 1B).

Table 1. Body size and sample sizes of 3 species of blackline shiners Notropis spp. acclimated to clear and turbid water treatments and tested for routine metabolic rate $(\mathrm{RMR})$ and critical oxygen tension $\left(P_{\text {crit }}\right)$. SL: standard length

\begin{tabular}{|c|c|c|c|c|c|c|c|}
\hline Species & Parameter & Treatment & $\mathrm{N}$ & $\begin{array}{c}\text { Mass } \\
\text { range }(g)\end{array}$ & $\begin{array}{c}\text { Mean } \\
\text { mass (g) }\end{array}$ & $\begin{array}{l}\text { SL range } \\
\text { (cm) }\end{array}$ & $\begin{array}{c}\text { Mean } \\
\text { SL }(\mathrm{cm})\end{array}$ \\
\hline \multirow[t]{4}{*}{ Blacknose } & \multirow[t]{2}{*}{ RMR } & Clear & 7 & $0.38-1.63$ & 0.96 & $3.5-5.0$ & 4.4 \\
\hline & & Turbid & 6 & $0.54-1.75$ & 1.10 & $4.6-5.4$ & 4.8 \\
\hline & \multirow[t]{2}{*}{$P_{\text {crit }}$} & Clear & 8 & $0.38-1.63$ & 0.95 & $3.5-5.0$ & 4.4 \\
\hline & & Turbid & 7 & $0.54-1.75$ & 1.15 & $4.5-5.4$ & 4.8 \\
\hline \multirow[t]{4}{*}{ Bridle } & \multirow[t]{2}{*}{ RMR } & Clear & 4 & $0.65-1.27$ & 0.99 & $4.1-4.9$ & 4.4 \\
\hline & & Turbid & 5 & $0.71-1.42$ & 1.07 & $3.8-4.6$ & 4.2 \\
\hline & \multirow[t]{2}{*}{$P_{\text {crit }}$} & Clear & 5 & $0.65-1.27$ & 0.99 & $4.1-4.9$ & 4.4 \\
\hline & & Turbid & 5 & $0.71-1.42$ & 1.07 & $3.8-4.6$ & 4.2 \\
\hline \multirow[t]{4}{*}{ Pugnose } & \multirow[t]{2}{*}{ RMR } & Clear & 5 & $0.33-1.73$ & 1.06 & $2.7-4.7$ & 4.0 \\
\hline & & Turbid & 7 & $0.49-1.58$ & 1.00 & $3.3-4.7$ & 4.1 \\
\hline & \multirow[t]{2}{*}{$P_{\text {crit }}$} & Clear & 5 & $0.33-1.73$ & 1.06 & $2.7-4.7$ & 4.0 \\
\hline & & Turbid & 7 & $0.49-1.58$ & 1.00 & $3.3-4.7$ & 4.1 \\
\hline
\end{tabular}



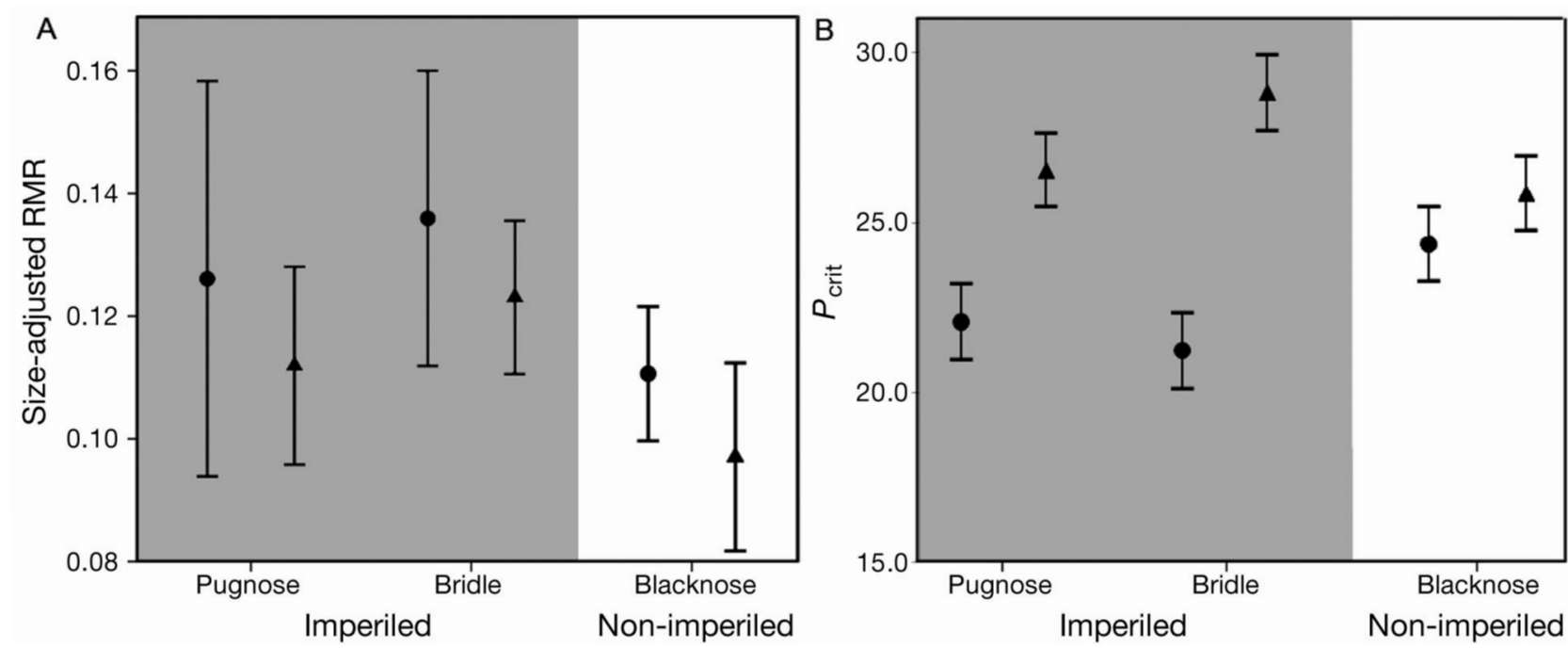

Fig. 1. Mean \pm SE (A) size-adjusted resting metabolic rate (RMR) and (B) critical oxygen tension ( $\left.P_{\text {crit }}\right)$ in 2 imperiled (pugnose shiner Notropis anogenus, bridle shiner $N$. bifrenatus; grey panel) and 1 non-imperiled (blacknose shiner $N$. heterolepis; white panel) blackline shiner species exposed to clear (circles) or turbid (triangles) conditions for at least 3 mo. Anti-log means are presented for the $P_{\text {crit }}$ data. The difference between $P_{\text {crit }}$ values for imperiled fish in clear vs. turbid treatments was the only significant effect (see Table 2)

Table 2. Results of ANOVAs testing for differences between clear- and turbid-acclimated blackline shiners Notropis spp. in resting metabolic rate (RMR) and critical oxygen tension $\left(P_{\text {crit }}\right)$. Separate ANOVAs are reported for the non-imperiled blacknose shiner $N$. heterolepis and the imperiled species group (pugnose $N$. anogenus and bridle shiner $N$. bifrenatus). Bold type indicates significance at $\alpha=0.05$

\begin{tabular}{|lccccc|}
\hline Group & Parameter & Effect & $F$ & df & p \\
\hline Non- & RMR & Treatment & 0.514 & 1,11 & 0.477 \\
imperiled & $P_{\text {crit }}$ & Treatment & 0.113 & 1,13 & 0.742 \\
Imperiled & RMR & Treatment & 0.376 & 1,17 & 0.548 \\
& & Species & 0.226 & 1,17 & 0.641 \\
& & Treatment $\times$ Species & 0.001 & 1,17 & 0.977 \\
& $P_{\text {crit }}$ & Treatment & 8.258 & 1,18 & $\mathbf{0 . 0 0 9}$ \\
& & Species & 0.039 & 1,18 & 0.846 \\
& & Treatment $\times$ Species & 0.565 & 1,18 & 0.462 \\
\hline
\end{tabular}

\section{DISCUSSION}

We found evidence to suggest a negative effect of long-term exposure to low levels of turbidity on the aerobic capacity of the imperiled shiners. While there was no effect of turbidity on metabolic rate in any of the species, $P_{\text {crit }}$ was higher in turbid vs. clear treatments in the imperiled species, viz. pugnose and bridle shiners, compared to the more common blacknose shiner in which no response was detected (Fig. 1B). A higher $P_{\text {crit }}$ after exposure to turbidity suggests that pugnose and bridle shiners are less capable of regulating $\mathrm{VO}_{2}$ than when held in clear water. This could be due to damaged or mucus- clogged gills effectively creating a localized hypoxic state for individual fish such that oxygen uptake becomes difficult. We did observe a build-up of mucus on the gills of some of the imperiled fish postmortem, but quantification of gill damage remains the topic of future study. Blacknose shiner did not appear to be affected by this low level of turbidity used or the duration of exposure to turbidity, consistent with previous findings (Gray et al. 2014). The strength of inferences we can draw are limited by the number of imperiled vs. non-imperiled species in our study and the sample size for some groups. Although collection of endangered species must be strongly justified, additional work with these blackline shiners could be very informative in revealing fitness and population-level responses to low levels of turbidity, given the variation in endangerment across species. However, the species-specific physiological response to long-term exposure to elevated turbidity levels is consistent with the behavioral and swimming performance results we attained for the same species in an earlier study (Gray et al. 2014).

The level of turbidity used here was relatively low (see Collins et al. 2011), although within the range known to elicit behavioral and physiological responses in a variety of species (e.g. Collins et al. 2011) and higher than in sites where we collected the imperiled pugnose and bridle shiners (Gray et al. 2014). In addition, the respirometry equipment is particularly sensitive to suspended particulates and, therefore, we were only able to run trials under clear 
conditions. Running trials under differing treatment conditions would have been ideal and, along with a larger sample size, may have strengthened the species-specific results; however, the pattern of response to low turbidity observed in the imperiled species indicates a relevant negative response to this stressor. The consequences of higher $P_{\text {crit }}$ in imperiled shiners could be compounded by other stressors, such as hypoxia (i.e. low DO) and increased water temperature predicted by climate change models (Pörtner 2010). Warmer water can impose an energetic challenge for ectotherms if it pushes them to the edge of their thermal tolerance or results in increased metabolic rates (He et al. 2015, McDonnell \& Chapman 2015).

Our results suggest that long-term exposure to low levels of sedimentary turbidity as a single stressor can have negative consequences for the physiology of imperiled fishes. To evaluate the overall response of blackline shiners to low levels of sedimentary turbidity, we calculated the mean percent change in behavior (Gray et al. 2014) and physiology (present study) for each species (Fig. 2). Each value was calculated by taking the absolute difference between clear and turbid treatments for each response variable (i.e. schooling behavior, critical swimming speed, RMR, and $\left.P_{\text {crit }}\right)$ and then calculating the mean relative response for each species. This qualitative examination reveals that across a number of sub-lethal be-

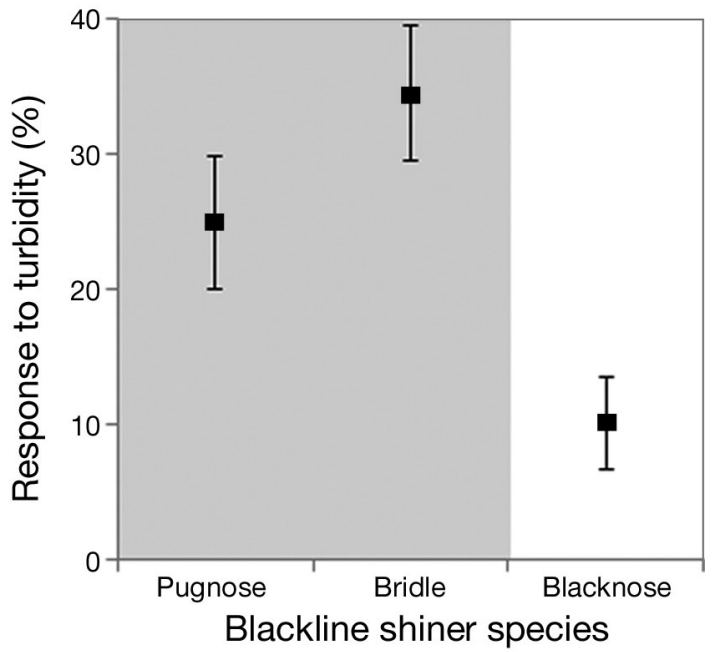

Fig. 2. Response of imperiled pugnose shiner Notropis anogenus and bridle shiner $N$. bifrenatus (grey panel) and the more common blacknose shiner $N$. heterolepis (white panel) exposed to low levels ( $<15$ NTU) of sedimentary turbidity. Values represent the mean $( \pm \mathrm{SE})$ of the percent differences between clear- and turbid-acclimated fish for schooling behavior and critical swimming speed (data from Gray et al. 2014), and resting metabolic rate and critical oxygen tension (data from the present study) havioral and physiological traits, there is substantial inter-specific variation in response to turbidity, with the most pronounced difference found between the imperiled and non-imperiled species. These effects would likely be compounded by other humaninduced stressors prevalent in freshwater systems such as hypoxia and increasing temperatures that present energetically demanding environments.

Recent efforts have been made to understand the mechanisms driving species loss and to integrate this knowledge toward a more holistic conservation plan under the framework of conservation physiology (Cooke et al. 2014). Our work highlights the importance of understanding species-specific behavioral and physiological responses to key environmental stressors. Next steps include determining thresholds for sub-lethal responses and ascertaining whether reversal of stressor treatments results in a return to normal behavioral and physiological processes.

Acknowledgements. We thank 3 anonymous referees for their review of this manuscript. We thank the Fisheries and Oceans Canada field crew for help collecting fishes, and J. Hunter, C. Friesen, K. Gong, K. Smith, and S. Guan for fish care. This work was approved by the McGill University Animal Care Committee (Protocol no. 5889), Canada Centre for Inland Waters Animal Care Committee, and Fisheries and Oceans Canada (Permit Sect 73 SARA C\&A 10-015). Funding was provided to S.M.G. by a North American Native Fishes Association Research Grant and National Science and Engineering Research Council (NSERC) Visiting Fellowship in a Canadian Government Lab; to L.J.C. by NSERC Canada Research Chair funds; and to N.E.M. by the Fisheries and Oceans Canada Species at Risk Program. We declare no conflict of interest.

\section{LITERATURE CITED}

Brett JR (1964) The respiratory metabolism and swimming performance of young sockeye salmon. J Fish Res Board Can 21:1183-1226

> Candolin U, Salesto T, Evers M (2007) Changed environmental conditions weaken sexual selection in sticklebacks. J Evol Biol 20:233-239

Chapman LJ (2015) Low-oxygen lifestyles. In: Riesch R, Tobler M, Plath M (eds) Extremophile fishes: ecology, evolution, and physiology of teleosts in extreme environments. Springer, Basel, p 9-34

> Clark TD, Sandblom E, Jutfelt F (2013) Aerobic scope measurements of fishes in an era of climate change: respirometry, relevance and recommendations. J Exp Biol 216: 2771-2782

Collins A, Naden P, Sear D, Jones J, Foster I, Morrow K (2011) Sediment targets for informing river catchment management: international experience and prospects. Hydrol Processes 25:2112-2129

Cooke SJ, Blumstein DT, Buchholz R, Caro T and others (2014) Physiology, behavior, and conservation. Physiol Biochem Zool 87:1-14 
Donohue I, Garcia Molinos J (2009) Impacts of increased sediment loads on the ecology of lakes. Biol Rev Camb Philos Soc 84:517-531

Gray SM, Chapman LJ, Mandrak NE (2012) Turbidity reduces hatching success in threatened spotted gar (Lepisosteus oculatus). Environ Biol Fishes 94:689-694

Gray SM, Bieber FME, McDonnell LH, Chapman LJ, Mandrak NE (2014) Turbidity effects vary among closely related fishes: implications for conservation. Aquat Conserv 24:546-560

He W, Cao ZD, Fu SJ (2015) Effect of temperature on hypoxia tolerance and its underlying biochemical mechanism in two juvenile cyprinids exhibiting distinct hypoxia sensitivities. Comp Biochem Physiol Part A Mol Integr Physiol 187:232-241

Hendry AP, Taylor EB (2004) How much of the variation in adaptive divergences can be explained by gene flow? An evaluation using lake-stream stickleback pairs. Evolution 58:2319-2331

Holm E, Mandrak NE (2002) Update COSEWIC status report on the Pugnose shiner, Notropis anogenus, in Canada. In: COSEWIC assessment and update status report on the Pugnose shiner, Notropis anogenus, in Canada. Committee on the Status of Endangered Wildlife in Canada

Kemp P, Sear D, Collins A, Naden P, Jones I (2011) The impacts of fine sediment on riverine fish. Hydrol Processes 25:1800-1821

McDonnell LH, Chapman LJ (2015) At the edge of the thermal window: effects of elevated temperature on the resting metabolism, hypoxia tolerance and upper critical thermal limit of a widespread African cichlid. Conserv Physiol 3:cov050

Metcalfe NB, Van Leeuwen TE, Killen SS (2016) Does individual variation in metabolic phenotype predict fish behaviour and performance? J Fish Biol 88:298-321

Editorial responsibility: Steven Cooke, Ottawa, Ontario, Canada
Newcombe C, MacDonald D (1991) Effects of suspended sediments on aquatic ecosystems. N Am J Fish Manag $11: 72-82$

Pörtner HO (2010) Oxygen- and capacity-limitation of thermal tolerance: a matrix for integrating climate-related stressor effects in marine ecosystems. J Exp Biol 213: 881-893

Reardon EE, Chapman LJ (2010) Energetics of hypoxia in a mouth-brooding cichlid: evidence for interdemic and developmental effects. Physiol Biochem Zool 83: 414-423

Reardon EE, Parisi A, Krahe R, Chapman LJ (2011) Energetic constraints on electric signalling in wave-type weakly electric fishes. J Exp Biol 214:4141-4150

> Ricciardi A, Rassmusen JB (1999) Extinction rates of North American freshwater fauna. Conserv Biol 13:1220-1222

> Rosenfeld JS, Hatfield T (2006) Information needs for assessing critical habitat of freshwater fish. Can J Fish Aquat Sci 63:683-698

Sutherland AB, Meyer JL (2007) Effects of increased suspended sediment on growth rate and gill condition of two southern Appalachian minnows. Environ Biol Fishes 80: 389-403

Trautman MB (1981) The fishes of Ohio. Ohio State University Press, Columbus, OH

Trebitz AS, Brazner JC, Brady VJ, Axler R, Tanner DK (2007) Turbidity tolerances of Great Lakes coastal wetland fishes. N Am J Fish Manag 27:619-633

Ultsch GR, Boschung H, Ross MJ (1978) Metabolism, critical oxygen tension, and habitat selection in darters (Etheostoma). Ecology 59:99-107

> Yang Y, Cao ZD, Fu SF (2015) Variations in temperature acclimation effects on glycogen storage, hypoxia tolerance and swimming performance with seasonal acclimatization in juvenile Chinese crucian carp. Comp Biochem Physiol Part A Mol Integr Physiol 185:16-23

Submitted: May 6, 2016; Accepted: September 17, 2016 Proofs received from author(s): November 6, 2016 